\title{
Developing Intercultural Competence Through Design Thinking
}

\section{Tetiana Hantsiuk}

Ivano-Frankivsk National Technical University of Oil and Gas, Ivano-Frankivsk, Ukraine

\section{Khrystyna Vintoniv}

Ivano-Frankivsk National Technical University of Oil and Gas, Ivano-Frankivsk, Ukraine

\section{Nataliia Opar}

Ivano-Frankivsk National Technical University of Oil and Gas, Ivano-Frankivsk, Ukraine

\section{Bohdan Hryvnak}

Ivano-Frankivsk National Technical University of Oil and Gas, Ivano-Frankivsk, Ukraine

\section{Crossiref}

http://dx.doi.org/10.5755/j01.eis.1.15.28930

Cultural competence, as the ability to interact effectively with the culturally diverse others, is a key component to your success in the globalized world. Developing cultural competence gives us an insight how to benefit from the diversity within intercultural interactions. Everyone may misinterpret the cultural differences due to the low level of cultural competence. That can influence further cooperation with different cultures. Therefore, it is very important to foster students' intercultural skills, in particular by using different learning techniques and implementing new ideas into the traditional teaching methods. One of them isdesign thinking as a practice that encourages collaboration and can help students to manage intercultural challenges. Hence, the research problem for this study is to reveal the correlation between the development of students' intercultural competence and design thinking method application.

The purpose of the study is to summarize and synthesize the research on cross-cultural interactions and design thinking to build a framework that shows how the implementation of the design thinking method into the learning process facilitates the development of students' intercultural competence.

The tasks of the research are:

a to review the main contributions to the field of design thinking by analysing multidisciplinary studies on how design thinking fosters development of variety competences including intercultural competence;

b to design the framework to reveal the correlation between the components of intercultural competence and the stages of design thinking process;

c to observe the changes in the students' intercultural competence level by analysing learners' responses to the case of intercultural misunderstanding at the beginning of studying the cross-cultural communication classes and after finishing the course.

d The study uses mixed approaches such as quantitative and qualitative methods, scientific literature studies, intercultural competence assessment, grouping, comparative analysis, synthesis, inductive and deductive methods.

The key results are presented in the framework that demonstrates the ways how design thinking method supports the development of intercultural competence. This framework can be used by educators to teach intercultural competence and everyone involved in cross-cultural interactions, and who would like to benefit from the diversity.

KEYWORDS: cultural diversity, culture, design thinking, intercultural communication, intercultural competence.
EIS 15/2021

Developing Intercultural Competence Through Design Thinking

Submitted 03/2021

Accepted for publication 06/2021

\section{Abstract}

\section{ktu}

1922

European Integration Studies No. 15 / 2021, pp. 9-21 doi.org/10.5755/j01.eis.1.15.28930 
In today's extremely globalized world the role of intercultural interactions and cultural competence accordingly has increased. The establishment of international contacts requires not only good communication skills but also a high level of intercultural competence because the lack of cultural understanding increases the probability of cross-cultural differences and problems occurrence.

Cultural competence refers to the "process by which individuals and systems respond respectfully and effectively to people of all cultures, classes, races, ethnic backgrounds, religions, and other diversity factors in a manner that recognizes, affirms and values the worth of individuals, families and communities, and protects and preserves the dignity of each" (National Association of Social Workers, 2015).

Numerous attempts were made to define this concept regarding intercultural competence. In its broadest sense, intercultural competence is defined as "a complex of abilities needed to perform effectively and appropriately when interacting with others who are linguistically and culturally different from oneself" (Fantini et al., 2006). The intercultural competence should be constantly developed as it gives us an insight how to benefit from the diversity within intercultural interactions. Everyone may misinterpret the cultural differences due to the low level of cultural competence. It can influence further cooperation with different cultures. Therefore, it is very important to foster students' intercultural skills, in particular by using different learning techniques and implementing new ideas into the traditional teaching methods. One of them is design thinking as a practice that encourages collaboration and can help students to manage intercultural challenges. Hence, the research problem for this study is to reveal the correlation between the development of students' intercultural competence and design thinking method application.

This article aims to summarize and synthesize the research on cross-cultural interactions and design thinking to build a framework that shows how the implementation of the design thinking method into the learning process facilitates the development of students' intercultural competence.

The article sets the following tasks:

a to review the main contributions to the field of design thinking by analysing multidisciplinary studies on how design thinking fosters development of variety competences including intercultural competence;

b to design the framework to reveal the correlation between the components of intercultural competence and the stages of design thinking process;

c to observe the changes in the students' intercultural competence level by analysing learners' responses to the case of intercultural misunderstanding at the beginning of studying the Intercultural Communication classes and after finishing the course.

Research Methodology includes the pre-course and post-course survey conducted at Intercultural Communication course in which 89 undergraduate students from six academic groups were enrolled since 2018. For the purpose of this research, the generally accepted quantitative and qualitative methods, scientific literature studies, intercultural competence assessment, grouping, comparative analysis, synthesis, inductive and deductive methods have been applied.

Literature review

The aim of design thinking is to develop a variety of competencies and skills. Many scholars have written about how to implement design thinking into the educational process to better prepare students for the $21^{\text {st }}$ century workplace. We selected 14 papers out of 50 for a meta-synthesis review focusing mainly on five key competences: 1) creative competence, 2) problem-solving competence, 3) project competence, 4) communication competence (including foreign language competence), and 5) intercultural competence.

The first group includes 3 articles about creative competence. R. Steinbeck (2011) considers de- 
sign thinking as a human-centred creativity approach and shares their experience about the implementation at a Stanford University and a university of Colombia. The other authors (Kijima et al., 2021) analyse a 3-day design thinking workshop in Japan and reveal that female youths showed greater creative confidence such as voicing their opinions and attitudes toward failures. According to R. Clark et al. (2020), applying design thinking in an engineering course can foster students' creativity and sustainability.

The second group is based on the analysis of 3 articles about problem-solving competence. On the basis of different universities in Latvia A. Vintere (2019) considers four approaches to developing problem-solving skills in higher education and one of them is design thinking. The other authors (Melles et al., 2015) discuss the problem-solving nature of design thinking and compare it to problem-based learning and enquiry-based learning approaches. Following D. Piotrowska (2015), prototyping from design thinking method can improve creativity and innovation in problem solving.

The third group reviews 3 articles about project competence. Z. Galeeva et al. (2018) tested a five-step model and successfully implemented design thinking process in teaching to develop students' project thinking ability. In (Serpes et al., 2017) the authors underline the importance of introducing design thinking in management schools to make students innovation-ready and present a conceptual model with five key learnings. The research (Lebid et al., 2020) is based on several Ukrainian universities and it examines how students can learn design thinking skills through participation in project-based activity.

The fourth group outlines 3 articles about communication competence. The new interesting approach is described by Z. Sandorova (2019) as the author uses design thinking in teaching English for tourism students and analyses the advantages and disadvantages of this method. Another author (Pope-Ruark, 2019) interviewed four teachers to discover the correlation between design thinking and technical and professional communication programs. A new approach to design thinking is presented by L. Borissova (2020) that suggests using design thinking in written communication as it can help to gain specific knowledge and skills.

The fifth group presents only 2 articles about developing intercultural competence. K. Thoring, C. Luippold and R. Mueller (2014) demonstrate how culture can affect the design thinking process in an educational environment. The authors created the framework by mapping six design thinking parameters to $G$. Hofstede's five cultural dimensions, demonstrating that different values in each cultural dimension influence the ability to adjust design thinking requirements such as process, team, space, and mind-set. N. Schadewitz in her research (2009) developed eleven design patterns for cross-cultural collaboration showing that diverse cultures have a lot of design solutions to facilitate collaborative activities.

There are numerous publications concerning the first four groups. We chose three articles that we consider the most relevant in each group but managed to find only two articles for the fifth group. Thus, the review of the literature reveals a research gap in understanding how design thinking can help to strengthen students' intercultural competence.

For the purpose of this research, intercultural competence is defined as the set of attitudes, knowledge and skills that are necessary for effective interactions with people who are culturally different from each other. This approach was well developed by the Association of American Colleges and Universities (AAC\&U, 2009) that represents more than a hundred colleges and universities across the United States. They suggested the Intercultural Knowledge and Competence Value Rubric which determines the following six key components of intercultural competence:
Conceptualization of European identity

Theoretical Background 
1 attitude of openness is expressed when you develop interactions with people from other cultures and you value these interactions without making any judgements;

2 attitude of curiosity leads to asking sophisticated questions about other cultures and articulating answers to these questions that represent different cultural viewpoints;

3 knowledge of cultural self-awareness means that you shape understanding of your own cultural rules and biases;

4 knowledge of cultural worldview frameworks shows that you realise the complexity of elements important to members of another culture;

5 with skills of nonverbal and verbal communication you can understand cultural differences in verbal and nonverbal communication and negotiate effectively in accordance with these differences;

6 skills of empathy are the ability to analyse intercultural experience from both your own perspective and several other worldviews and to act respectfully taking into account the feelings of another cultural group.

To illustrate components of intercultural competence we suggest the Cube Model in which six sides represent each intercultural competence element (Figure 1).

Figure 1

Intercultural Competence Cube Model

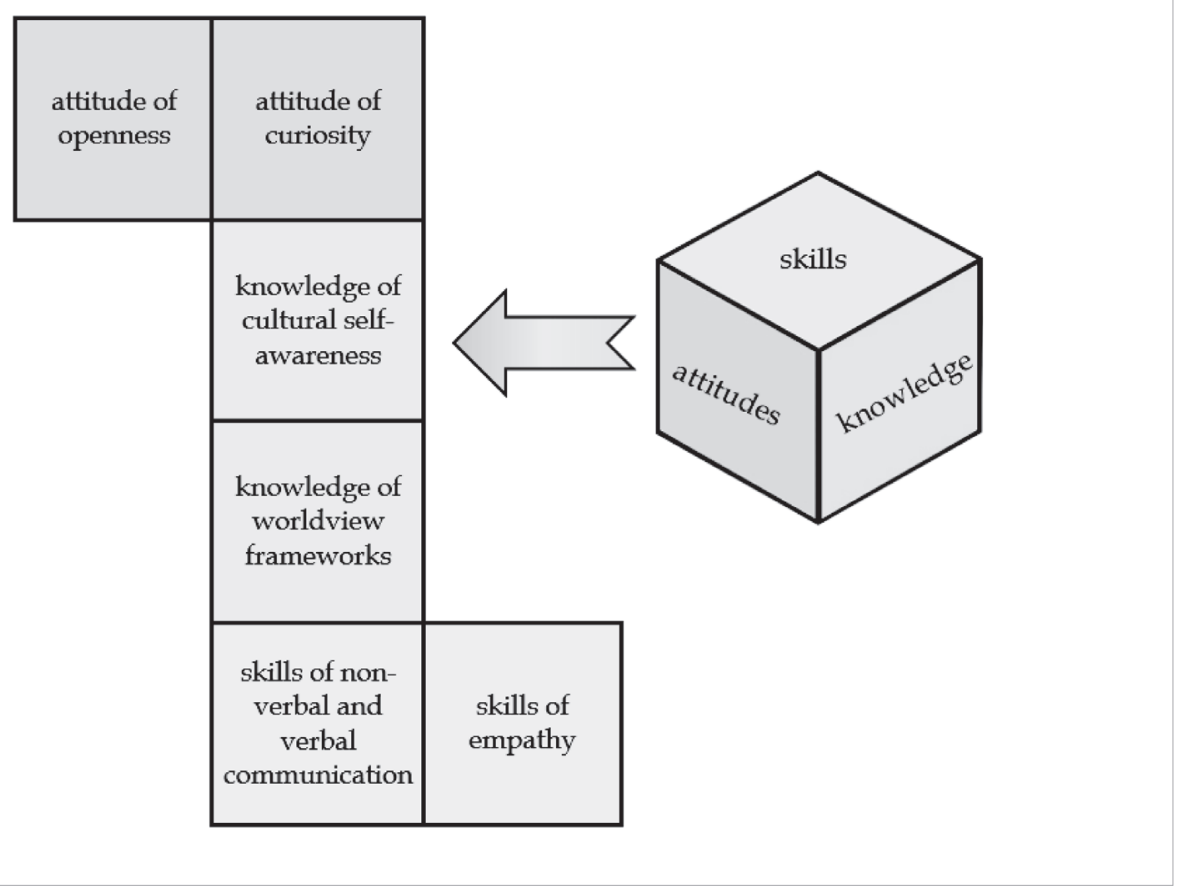

In this paper we intend to develop intercultural competence by the means of design thinking, so it is important to define the concept of design thinking. Design thinking can be conceived as a "human-centred methodology" that supports and drives effective innovation (Bauer et al., 2008). According to T. Brown, "design thinking is widely understood as a human-centred approach to innovation that includes inspiration, ideation and implementation that appears equally cyclical and iterative understanding people as inspiration, prototyping, building to think, using stories, and having an inspired and inspiring culture" (Brown, 2008). There are variety of design thinking models but the most noticeable of them is the model designed by the HPI School of Design 
Thinking (Plattner et al., 2009). According to this model, design thinking process comprises six stages. Referring back to our research aim, we reviewed the stages described in (Hasso Plattnet Institut; Carroll et al., 2010; Müller-Roterberg, 2018) and we understand them as following:

" "Understand" is about developing an understanding of the challenge, the problem, the need or the requirement;

" "Observe" is the phase of detailed research and on-site observations that are carried out on the customer's need or problem;

„ "Point of View" is the step to consider information about users' needs and to create so-called "persona" to see the problem from users' perspective;

" "Ideate" is the stage to practice brainstorming to generate as many ideas as possible, then to structure the ideas and to vote to choose the one for realization;

" "Prototype" is used to create a simple model to visualize the idea of problem solution;

" "Test" is the final stage where the model we created should be tested with the people it was designed for to learn if it works. The aim of this stage is to get the feedback and to improve the solution.

Thus, design thinking is "a human-centred approach to innovation," (Carlgren et al., 2016), and it is used "to guide the instruction of traditional subjects to cultivate students' $21^{\text {st }}$ century skills" (Lin et al., 2020), in particular, this innovative approach can be applied to foster intercultural competence in educational settings.

The research was conducted at Intercultural Communication course (9 ECTS credits) at the Ivano-Frankivsk National Technical University of Oil and Gas in Ivano-Frankivsk, Ukraine. The participants were 89 undergraduate students from six academic groups enrolled in the course since 2018. At the beginning of the course the students voluntarily responded to three open questions based on intercultural misunderstanding case and after finishing the course the same students were invited to participate in the post-course survey based on the same cross-cultural misunderstanding case and were asked to respond to the same questions to reveal the changes in their intercultural competence levels. All the students identified themselves as the Ukrainians.

The Council of Europe White Paper on Intercultural Dialogue states that the intercultural approach is a forward-looking model for managing cultural diversity (Council of Europe, 2008). The document argues that teaching and learning intercultural competences is one of certain preconditions that should be met in order for intercultural dialogue to thrive, and assigns to education professionals the specific responsibility of fostering intercultural competences in learners. The appropriate forms of intercultural education can have a significant impact on the intercultural competence of young people (Barrett, 2012).

The promotion of intercultural competence is crucial for tackling some of the most profound challenges that European societies currently face (Barrett, 2018). Intercultural Communication classes may help foster intercultural competence to get the students ready for future cross-cultural interactions. We have been implementing the design thinking practice into teaching intercultural competence at the Ivano-Frankivsk National Technical University of Oil and Gas and have been observing the changes in the students' intercultural competence level by analysing learners' responses to the case of intercultural misunderstanding at the beginning of studying the cross-cultural communication classes and after finishing the course.

We considered six academic groups that took cross-cultural communication classes since 2018 , i. e., the changes in 89 students' intercultural competence levels were observed over the last four years. The students were presented with the case ${ }^{1}$ of cross-cultural misunderstanding in-
Research Methodology

Findings 
troduced by Chuck Calahan in the MOOC "Improve Your Intercultural Competence" at the British digital education platform (FutureLearn) and after that, they were asked to reflect on three questions that were to show the level of students' intercultural competence:

How do you think you would feel and what you would do if you went through this critical incident? (the attitude of openness, the attitude of curiosity).

What actually happened in the situation described? (knowledge of cultural self-awareness, knowledge of worldview frameworks).

How do you think the indigenous woman felt in this case? (skills of non-verbal and verbal communication, skills of empathy).

As classroom talk analysis can illuminate the nature of discussions and illustrate how intercultural learning unfolds (Heggernes, 2021), classroom conversation was chosen to collect the responses. We consider each of these questions and students' responses at the beginning of the course. It should be mentioned that all of the Ukrainian students associated themselves with Mohle and her behaviour was accepted and familiar to them. The responses to the first question "How do you think you would feel and what you would do if you went through this critical incident?" could be drawn into three main categories:

" ignoring the situation (the responses like "I would find the other way to get to the office", "I would walk several more blocks to bypass that fruit and vegetable stand", "I would take the earphones not to hear her", etc.);

negative communication ("I would yell at her in return");

" positive communication ("I would explain her that I meant nothing bad", "I would ask her what is happening", "I would ask my co-workers why the woman behaves this way", etc.).

The questionnaire results illustrate that less than $8 \%$ of students would show openness in this situation of intercultural interaction, and only $5,6 \%$ would demonstrate an attitude of curiosity by asking questions about the reasons for the local's behaviour (Figure 2).

When responding to the second question ("What actually happened in the situation described?") all the students agreed about the intercultural misunderstanding. We would divide the possible answers into two:

" Mahle was misinterpreted, i. e., her nodding hello was misinterpreted by an indigenous lady;

" Mahle misinterpreted the local woman, i. e., clenched fist and the words might be misinterpreted by Mahle.

All the students supposed the girl to be misunderstood by the local woman ("The woman was offended by nodding", "The woman was insulted by eye contact", "The girl humiliated the elderly woman and showed disrespect by making eye contact", etc.), and just two students, i. e. 2,2\%, assumed that the meaning of indigenous gestures could also mean something different. In such a manner, the students demonstrated some level of cultural self-awareness as they were con-

\footnotetext{
1 Short scenario of the case (FutureLearn):

The case study involves a recent graduate of Purdue University who graduated with a degree in engineering and a minor in business administration. Mahle was hired by a very large, global equipment company. Mahle was given an assignment overseas with her company. She was living in an apartment just a few blocks away from her office, and on her way to work every morning in this foreign country, in a different culture, she began to have an experience with one of the indigenous people who lived there in that city. It was a manager of a fruit and vegetable stand, and as Mahle walked past the fruit and vegetable stand every morning on her way to work, this woman made eye contact with Mahle and Mahle nodded hello to her. However, one morning Mahle encountered what we call a critical incident. This elderly woman raised her arm in the air with a clenched fist and began yelling at Mahle: "Foreign girl! Foreign girl! Brown girl! Brown girl!!" Mahle initially felt uncomfortable and perhaps threatened, and so she started walking much faster to get to the office that particular morning. The same thing happened next morning, and the morning after that. My question for you is, how do you think you would feel if you went through this critical incident that Mahle just experienced?
} 


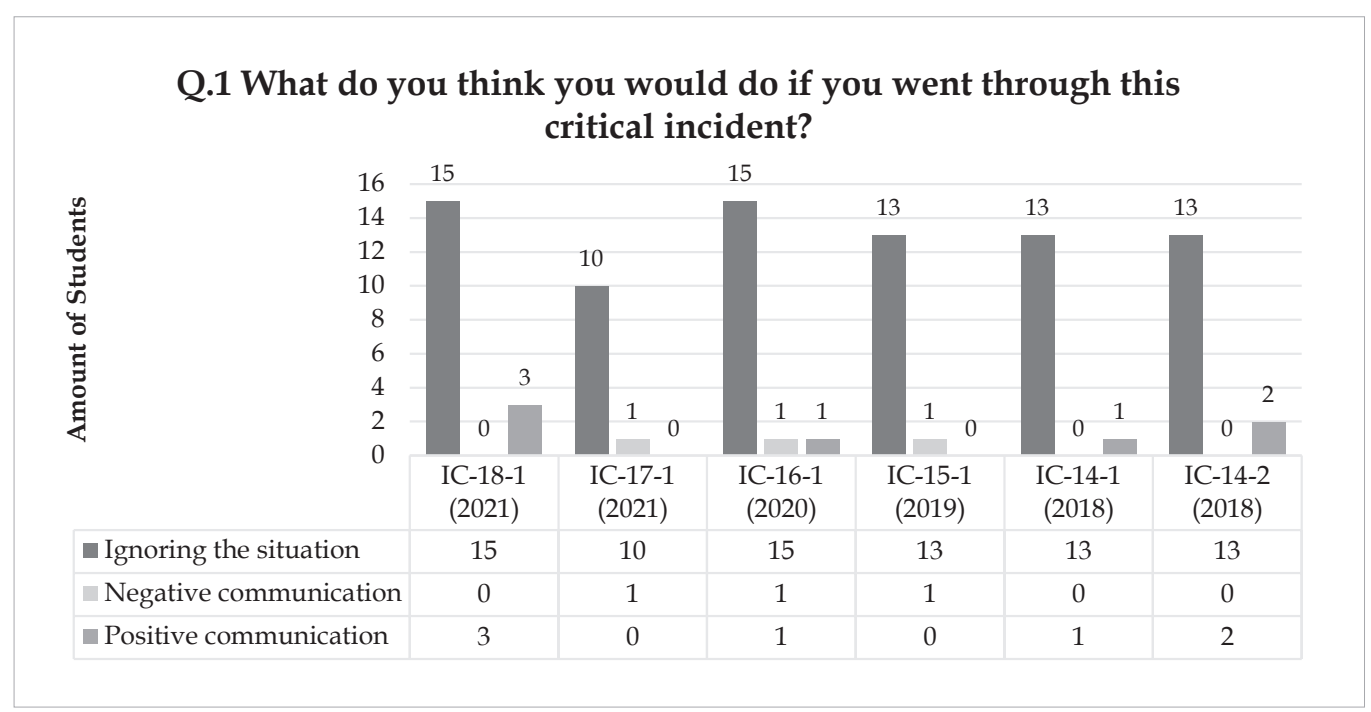

scious of the fact their behaviour is shaped by their cultures (nodding hello is an appropriate behaviour for them), but they missed the one that we also interpret the world based on our cultures (the yelling person makes us feel uncomfortable).

The respondents also showed the minimal knowledge of cultural worldview frameworks in the way that they were able to recognize that local people may perceive non-verbal cues in the manner their culture dictates (the woman might perceive nodding as an insult) and no more than one student expected the woman to behave depending on what is appropriate in her culture (communicating so loudly might be culturally determined manner of interaction).

Hence, the majority $(98,9 \%)$ of students demonstrated: 1$)$ knowledge of cultural self-awareness in a part of awareness of cultural influence on their own behaviour, and 2) knowledge of cultural worldview frameworks in a part of understanding of cultural effect on how people perceive the situation. Only 1,1\% responded in the way to show 1) knowledge of cultural self-awareness in both awareness of cultural influence on your own behaviour and awareness of cultural influence on your perception; 2) knowledge of cultural worldview frameworks in both understanding of cultural effect on how different people perceive the situation and understanding of cultural effect on how people act (Figure 3).

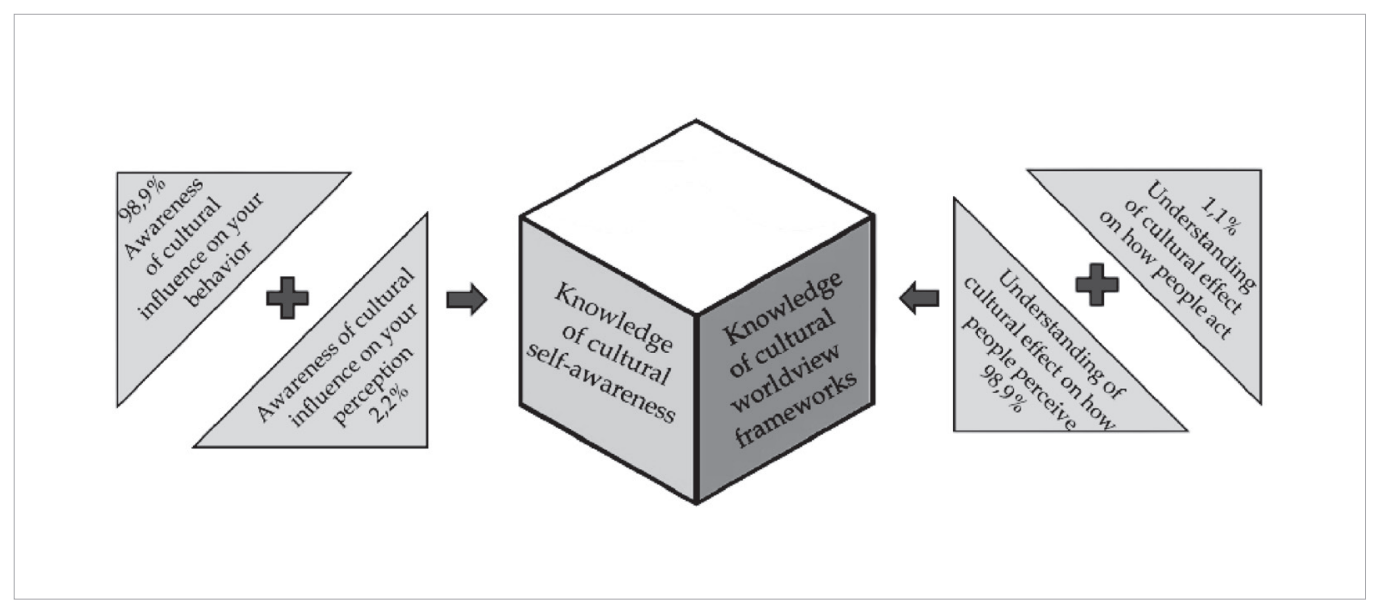

Figure 2

Students' reflections on the first question "What do you think you would do if you went through this critical incident?" at the beginning of studying Intercultural Communication course*

* IC-YY-N (YYYY) - the name of students' group, where IC - the specialty abbreviation, $\mathrm{YY}$ - the year of entrance, $\mathrm{N}$ - the group number, (YYYY) - the year of students' questionnaire

Figure 3

The components of cultural self-awareness and worldview frameworks knowledge 
We could only subjectively evaluate if the students have the skills of empathy and skills of non-verbal and verbal communication, based on their responses to the third question «How do you think the indigenous woman felt in this case?». We are able to see the correlation between the answer to the previous question and to this one. The students that demonstrated the knowledge of cultural self-awareness and the knowledge of cultural worldview frameworks $(1,1 \%$ of respondents) also showed the skills of empathy as long as wiliness to put themselves into the shoes of indigenous woman, to find out the reasons for her behaviour and the meaning of her verbal expressions and non-verbal cues. The rest of the students supposed that the local woman got angry for no logical reasons and there was no sense in demonstrating empathy.

In this way we outlined an approximate level of the students' intercultural competence at the beginning of studying Intercultural Communication. It was decided to "utilise design thinking to explore possible solutions to complex problems through interdisciplinary working in small groups" (Tang et al., 2020) and to apply the design thinking approach to such activities as learning through projects realization, case studies, role plays, simulations, and films analyses, that are all practised within the Intercultural Communication classes to develop intercultural competence.

When implementing the principles of design thinking into the process of teaching Intercultural Communication, we noticed that the above mentioned intercultural competence elements are interrelated with the design thinking stages. The process of obtaining intercultural competence in our interpretation looks like the stairs where to go upper you should pass the below steps first. To achieve the knowledge of cultural self-awareness and cultural worldview frameworks students must develop the attitudes of openness and curiosity, as well as they are able to gain the communication skills and skills of cultural empathy based on the knowledge of cultural self-awareness and cultural worldview frameworks.

The parallel could be drawn between the process of developing intercultural competence and the stages of design thinking as both come in a linear manner. We found out that each element of intercultural competence has the corresponding stage of design thinking process that develops the component the best.

For the purpose of this research, we consider the Design Thinking Process Model introduced by HPI D-School (Plattner et al., 2009) implemented into the students' project realization within Intercultural Communication classes. So, the Understanding and Observing design thinking stages foster the development of openness and curiosity attitudes as these stages involve interviewing, observation, and interpretation. During these stages team members try to gather as much information about the topic as possible which is achieved through the research (Thoring et al., 2011) and involves wiliness to interact with diverse people (practising openness in other words) and searching or asking for the relevant information (i. e., practising curiosity).

The main idea of Point of View and Ideation phases is to condense to a single prototypical user's (Müller-Roterberg, 2018) problems or needs and to generate solution-oriented ideas. In the context of intercultural communication projects realization, to perform these design thinking stages students should gain understanding of other person's needs and problems that might differ from their owns. This understanding consequently cultivates the development of cultural self-awareness and cultural worldview frameworks knowledge.

Prototyping and Testing Steps are intended to create a solution prototype and to test it. Elsback K. \& Stigliani I. (2018) stay that the design thinking tools, among others, typically include "developing a holistic understanding of user experience through customer journey mapping" and "require individuals to empathetically engage in learning about the user experience". Based on that insight we suggest that prototyping is suitable to practise empathy in the way that within 
this stage students try to feel the problem, to put themselves into the other person's shoes, to demonstrate "the ability to understand and respond to other people's thoughts, beliefs, values and feelings" (Council of Europe, 2014), and to create a prototype of the chosen solution. Furthermore, it is reasonable to train intercultural verbal and non-verbal skills during the testing stage within which students are able to practice intercultural communication and test their prototypes.

During each stage of design thinking we recommend to emphasize the development of certain intercultural competence element. In this way, the design thinking method application supports the development of students' intercultural competence most effectively. This approach is presented in the framework below (Figure 4).

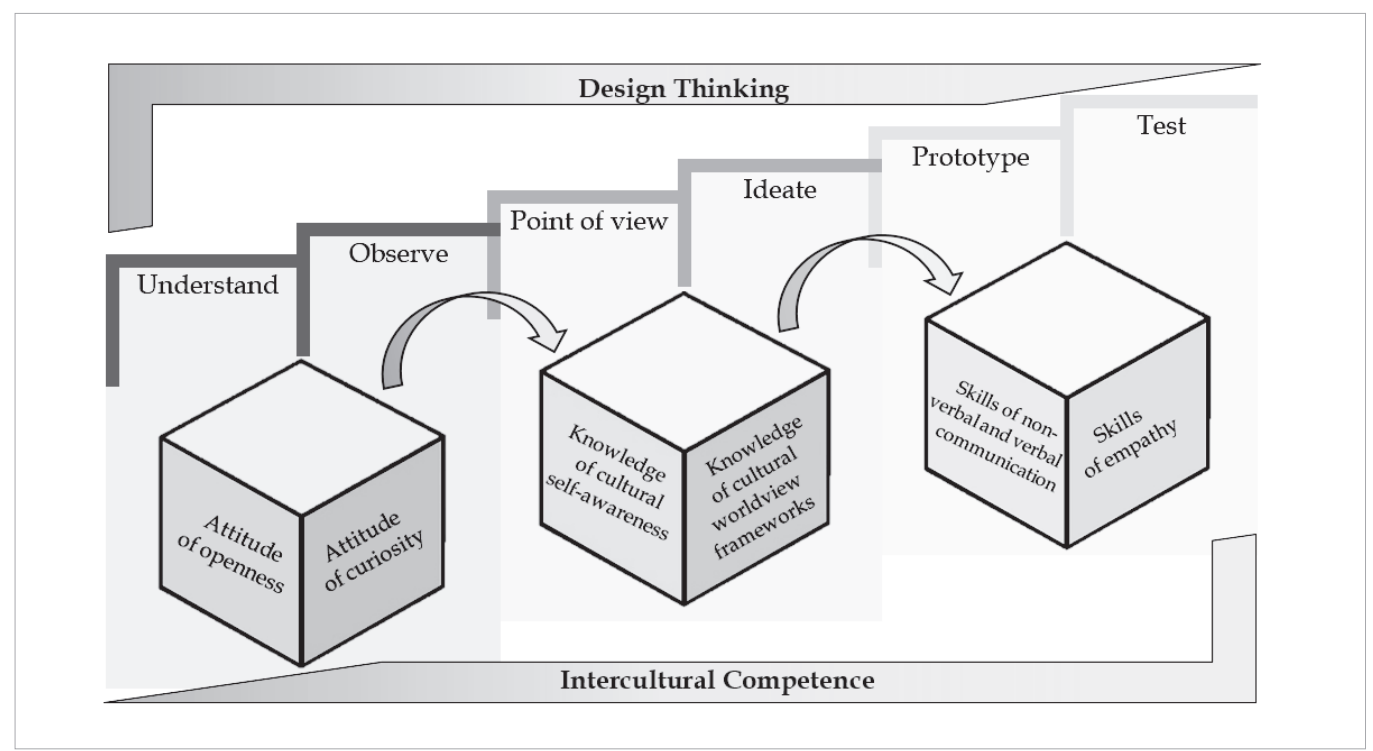

The Council of Europe (Council of Europe, 2014) states that since intercultural competence is a combination of attitudes, knowledge and understanding, skills and actions, assessment of intercultural competence development needs to include both analytical measurement - involving multiple measures - and holistic judgments of individuals' performance. That is the reason we decided to conduct the post-course survey after implementing the framework into Intercultural Communication course. After finishing the course the same students were invited to participate in the survey based on the same cross-cultural misunderstanding case they discussed the beginning of the course. The participants were asked to answer the same questions on how they would feel and behave if they found themselves in the same situation. The responses happened to differ from the ones before studying Intercultural Communication.

According to the first question responses, $91 \%$ of students demonstrated intercultural openness and almost $88 \%$ experienced curiosity trying to figure out the local's motives (Figure 5).

After finishing the course most of involved students couldn't answer the second question as they required some extra information. They concluded that Mahle acted in a way that was accepted for her and her reaction to the local woman's behaviour was shaped by her own assumptions. However, they couldn't explain the woman's behaviour. We interpret that as demonstrating the knowledge of cultural self-awareness and worldview frameworks. The participants supposed that the local responded based on what is appropriate for her and were reluctant to judge without additional information (Figure 6). Participating in other course activities besides case studies analysis students keep consciously asking questions such as "Why do I act the way I do?" and

\section{Figure 4}

The framework of correlation between the components of intercultural competence and stages of design thinking process 


\section{Figure 5}

Students' responses to the first questions "What do you think you would do if you went through this critical incident?" before starting and after finishing the course of Intercultural Communication

\section{Figure 6}

Students' level of cultural self-awareness and worldview frameworks knowledge assessment made up of the second question of the survey conducted at the beginning of studying Intercultural Communication course (Before) and after finishing it (After).

\section{Q.1 What do you think you would do if you went through this critical incident?}

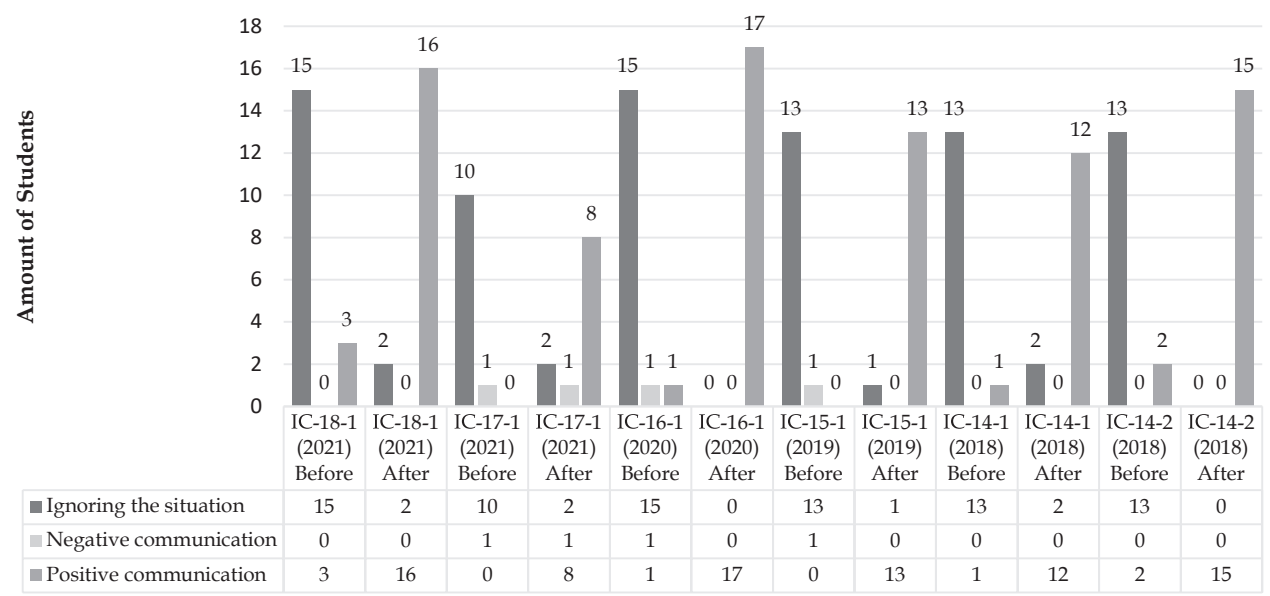

"Why do people behave in the manner they do?", or "How do I feel the situation?" and "How do people different from me perceive the same situation?" which also indicate the knowledge of cultural self-awareness and worldview frameworks.

Skills of empathy and skills of non-verbal and verbal communication are the last part of intercultural competence we evaluated within this research. The third question of the survey was asked for this purpose and these question responses also changed in comparison with the responses the students gave at the beginning of the course. The majority $(96,6 \%)$ of the respondents accepted that the indigenous woman's behaviour is shaped by her culture that may differ from theirs and concluded that they should understand and respect it.

Through this research we identified how the implementation of specific design thinking tools into education environment (particularly into the project realisation method) facilitates the development of specific intercultural competences within Intercultural Communication course. The framework of correlation between the components of intercultural competence and stages of design thinking process was designed to demonstrate these findings. 
This study is the first step to reveal the ways design thinking method implemented in learning environment influences the development of students' intercultural competence. Design thinking is widely discussed by the scientific community. This paper overviews multidisciplinary studies within the field of design thinking and identifies a research gap in existing literature on how design thinking can help to strengthen students' intercultural competence.

It is possible to draw a parallel between the process of developing intercultural competence and the stages of design thinking as both come in a linear manner. The key results suggest that each element of intercultural competence has the corresponding stage of design thinking process that develops the component the best. To demonstrate that correlation the framework as an approach to show the effectiveness of improving certain intercultural competence during each stage of design thinking process was designed for both educators' and researchers' usage.

The survey of undergraduate students for use in the research was conducted at the beginning and after finishing the Intercultural Communication course. We could observe the increase in students' intercultural competences such as attitudes of openness and curiosity, knowledge of cultural self-awareness and worldview frameworks, skills of empathy and skills of non-verbal and verbal communication. The questionnaire was intended to help educators to understand how design thinking implementation into learning environment affects students' intercultural competence level.

Intercultural competence can be taught in numerous ways and use various approaches, e. g. humour and irony (Gornostaeva, 2019) or heavy metal music (Guberman, 2020). However, based on the results of the study, we recommend educators to take into consideration our framework of students' intercultural competence and design thinking process correlation and to use design thinking method to develop intercultural competence at their classes. Our further research will try to determine how involving case studies and movies analysis in the learning process helps to develop students' intercultural competence.

Association of American Colleges and Universities (AAC\&U). (2009). VALUE. Retrieved March 18, 2021 from https://www.aacu.org/value

Barrett, M. (2012). Intercultural competence. EWC Statement Series, 2nd issue (pp. 23-27). Oslo, Norway: European Wergeland Centre. Retrieved from https:// www.researchgate.net/publication/265194528_Intercultural_Competence

Barrett, M. (2018). How schools can promote the intercultural competence of young people. European Psychologist, 23(1). 93-104. https://doi. org/10.1027/1016-9040/a000308

Bauer, R., \& Ward, E. (2008). Design thinking: Epistemic plurality in management and organization. Aesthesis, 2(3), 64-74.

Borrisova, L. G. (2020). Design thinking in written communication. Revista Inclusiones, 7, 106-112.

Brown, T. (2008). Design thinking. Harvard Business Review, 86 (6), 85-92. https://readings.design/PDF/ Tim\%20Brown,\%20Design\%20Thinking.pdf

Carlgren, L., Rauth, I., \& Elmquist, M. (2016). Framing design thinking: The concept in idea and enactment. Creativity and Innovation Management, 25 (1), 38-57.
DOI: 10.1111/caim.12153 https://doi.org/10.1111/ caim. 12153

Carroll, M., Goldman, S., Britos, L., Koh, J., Royalty, A., \& Hornstein, M. (2010). Destination, imagination and the fires within: design thinking in a middle school classroom. International Journal of Art \& Design Education. 29. 37-53. https://doi.org/10.1111/ j.1476-8070.2010.01632.x

Clark, R. M., Stabryla, L. M., \& Gilbertson, L. M. (2020). Sustainability coursework: student perspectives and reflections on design thinking. International Journal of Sustainability in Higher Education, 21, 593-611. https://doi.org/10.1108/IJSHE-09-2019-0275

Council of Europe (2008). White Paper on Intercultural Dialogue "Living Together As Equals in Dignity". Strasbourg, 7 May 2008. France: Committee of Ministers, Council of Europe. Retrieved from https:// www.coe.int/t/dg4/intercultural/source/white $\% 20$ paper_final_revised_en.pdf

Council of Europe (2014). Developing Intercultural Competence through Education. Strasbourg, January 2014. Retrieved from https://rm.coe.int/developing-intercultural-enfr/16808ce258
Conclusions
References 
Elsbach, K., \& Stigliani, I. (2018). Design thinking and organizational culture: a review and frameworkforfuture research. Journal of Management, January 2018, 44. https://doi.org/10.1177/0149206317744252

Fantini, A., \& Tirmizi, A. (2006). Exploring and assessing intercultural competence. World Learning Publications. Paper 1. Retrieved from http://digitalcollections.sit.edu/worldlearning_publications/1

FutureLearn. Intercultural Competence - Online course. Retrieved February 20, 2018, from https://www.futurelearn.com/courses/intercultural-competence

Galeeva, Z. N., Yao, M. K., Emanova, J. G., \& Pushkar, T. (2018). Project thinking as the basis of professional competence of the designer. Amazonia Investiga, 7, 133-138. Retrieved from https://amazoniainvestiga. info/index.php/amazonia/article/view/429/402

Gornostaeva, A. (2019). Humour and irony in the time of globalization: developing intercultural competence. Proceedings of INTED2019: 13th International Technology, Education and Development Competence, 4978-4982. https://doi.org/10.21125/ inted.2019.1241

Guberman, D. (2020). Teaching intercultural competence through heavy metal music. Arts and Humanities in Higher Education, 20, 115-132. https://doi. org/10.1177/1474022220903403

Hasso Plattnet Institut School of Design Thinking (HPI D-School). What is Design Thinking? Retrieved March 18, 2021, from https://hpi.de/en/school-ofdesign-thinking/design-thinking/what-is-designthinking.html

Heggernes, S. L. (2021). A critical review of the role of texts in fostering intercultural communicative competence in the English language classroom. Educational Research Review, 33. https://doi. org/10.1016/j.edurev.2021.100390

Kijima, R., Yang-Yoshihara, M., \& Maekawa, M. S. (2021). Using design thinking to cultivate the next generation of female STEAM thinkers. International Journal of STEM Education, 8. https://doi. org/10.1186/s40594-021-00271-6

Lebid, A. E., \& Shevchenko, N. A. (2020). Cultivation of the skills of design thinking via the project-based method as a component of the dual model of learning. European Journal of Contemporary Education, 9, 572-583. https://doi.org/10.13187/ejced.2020.3.572

Lin, L., Shadiev, R., Hwang, W. Y., \& Shen, S. (2020). From knowledge and skills to digital works: an application of design thinking in the information technology course. Thinking Skills and Creativity, Vol.36, June 2020. https://doi.org/10.1016/j.tsc.2020.100646

Melles, G., Anderson, N., Barrett, T., \& Thompson-Whiteside, S. (2015). Problem finding through design thinking in education. Inquiry-Based Learning for
Multidisciplinary Programs: A Conceptual and Practical Resource for Educators, 3, 191-209. https:// doi.org/10.1108/S2055-364120150000003027

Müller-Roterberg, C. (2018). Handbook of Design Thinking. Kindle Direct Publishing. ISBN: 978179043537. Retrieved from https://www.researchgate.net/publication/329310644_Handbook_of_ Design_Thinking

National Association of Social Workers (NASW). (2015). Standards and Indicators for Cultural Competence in Social Work Practice. Washington, DC: NASW. Retrieved from https://www.socialworkers.org/LinkClick.aspx?fileticket=PonPTDEBrn4\%3D\&portalid=0

Piotrowska, D. (2015). Problem based learning vs. design thinking - clash of best teaching practices. Proceedings of ICERI2015: 8th International Conference of Education, Research and Innovation, 1534-1538.

Plattner, H., Meinel, C., \& Weinberg, U. (2009). Design Thinking. Munich: Mi-Wirtschaftsbuch.

Pope-Ruark, R. (2019). Design thinking in technical and professional communication: four perspectives. Journal of Business and Technical Communication, 33, 437-455. https://doi. org/10.1177/1050651919854094

Sandorova, Z. (2019). Applying the method of design thinking in teaching ESP in the context of creative tourism. Proceedings of the 11 th Innovation in Language Learning International Conference, 297-300. Retrieved from https://www.researchgate.net/ publication/331496310_Applying_the_Method_ of_Design_Thinking_in_Teaching_ESP_in_the Context_of_Creative_Tourism

Schadewitz, N. (2009). Design patterns for cross-cultural collaboration. International Journal of Design, 3 (3), 37-53. Retrieved from http://www.ijdesign. org/index.php/IJDesign/article/view/276/273

Serpes, C., \& Menon, G. (2017). A conceptual model for introducing design thinking in management schools. Research into Design for Communities: Proceedings of ICoRD 2017, 2, 987-997. https://doi. org/10.1007/978-981-10-3521-0_83

Steinbeck, R. (2011). Building creative competence in globally distributed courses through design thinking. Comunicar, XIX (37), 27-34. https://doi. org/10.3916/C37-2011-02-02

Tang, T., Vezzani, V., \& Eriksson, V. (2020). Developing critical thinking, collective creativity skills and problem solving through playful design jams. Thinking Skills and Creativity, 37. ISSN 1871-1871. https://doi.org/10.1016/j.tsc.2020.100696

Thoring, K., \& Müller, M. R. (2011). Understanding design thinking: a process model based on method en- 
gineering. International Conference on Engineering and Product Design Education, 8 \& 9 September 2011 , City University, London, UK. Retrieved from https:// www.researchgate.net/publication/234065413_Understanding_design_thinking_A_process_model_ based_on_method_engineering

Thoring, K., Luippold, C., \& Mueller, R. (2014). The impact of cultural differences in design thinking education. Design Research Society's Conference. Retrieved from https://www.researchgate.net/ publication/261357176_The_Impact_of_Cultural_ Differences_in_Design_Thinking_Education

Vintere, A. (2019). Pedagogical approaches to problem solving in higher education. Research for Rural Development, 2, 255-259. https://doi. org/10.22616/rrd.25.2019.077

Research The paper was prepared within the framework of the joint Ukrainian-Lithuanian R\&D project Council of "Competence Development of Lithuanian and Ukrainian Public Sector Employees Using DeLithuania sign-Thinking Methodology". Agreement No. S-LU-20-5.

\section{HANTSIUK TETIANA}

$\mathrm{PhD}$ in Public Administration, Associate Professor Ivano-Frankivsk National Technical University of Oil and Gas, Ukraine

\section{Fields of interests}

Intercultural communication, information and analytical support mechanisms.

\section{Address}

15 Karpatska Str, Ivano-Frankivsk, 76019, Ukraine +380 997994222

tetiana.hantsiuk@nung.edu.ua

\section{OPAR NATALIIA}

PhD in Public Administration, Associate Professor Ivano-Frankivsk National Technical University of Oil and Gas, Ukraine

\section{Fields of interests}

Higher education quality, e-services, English academic writing.

\section{Address}

15 Karpatska Str, Ivano-Frankivsk, 76019, Ukraine +380 957825418

nataliia.opar@nung.edu.ua

\section{VINTONIV KHRYSTYNA}

PhD in History, Associate Professor

Ivano-Frankivsk National Technical

University of Oil and Gas, Ukraine

\section{Fields of interests}

Archives, Ukrainian diaspora, mass media.

\section{Address}

15 Karpatska Str, Ivano-Frankivsk, 76019 ,

Ukraine

+380 673429605

khrystyna.vintoniv@nung.edu.ua

\section{HRYVNAK BOHDAN}

PhD in Philosophy, Associate Professor

Ivano-Frankivsk National Technical

University of Oil and Gas, Ukraine

\section{Fields of interests}

Philosophy of education, science of law.

\section{Address}

15 Karpatska Str, Ivano-Frankivsk, 76019,

Ukraine

+380 506851024

bohdan.hryvnak@nung.edu.ua
About the authors 